\title{
Involvement of Plant Biologists in Undergraduate and High School Student Research
}

\author{
Jeffrey S. Coker* and Eric Davies
}

\begin{abstract}
A survey of the ASPB (American Society of Plant Biologists) was conducted through its Education Committee to determine the extent of member participation in support of undergraduate research and high school research. Analysis of this survey indicates that, of 531 total respondents, the vast majority $(88.5 \%)$ has supported undergraduate researchers in their laboratories, while a little less than half $(\mathbf{4 9 . 2 \%})$ have supported high school researchers. More than $80 \%$ of each participant group found their experiences rewarding. Among the most prevalent advantages mentioned were the pleasure of mentoring, the creation of an enthusiastic lab environment, and general motivation/learning in plant biology for the student. Many surveys reporting great successes with young researchers mentioned strategies for saving time, maximizing productivity, and utilizing resources wisely. On the other hand, the vast majority of disadvantage comments dealt with time issues such as the time spent by senior researchers training students, the time restraints of students, and the effects of training students on lab productivity.
\end{abstract}

$\mathrm{R}$ ECENT STUDIES assessing the prevalence and/or quality of research training for undergraduate and high school students are surprisingly scarce, while summaries of the perspectives of research mentors are nearly nonexistent. For the most part, the research training literature can be divided into three categories: nonspecific, large-scale accounts (Austin, 1997; Craig, 1999; Druger, 1998; Levesque and Wise, 2001; Schowen, 1998; Seago, Jr., 1992), descriptions of particular programs/courses (Boersma et al., 2001; Chaplin et al., 1998; Henderson and Buising, 2000; Heppner, 1996; Krasny, 1999; McLean, 1999; Nikolova Eddins et al., 1997; Ortez, 1994), and descriptions of particular training methods (Beer, 1995; Durso, 1997). Although each of these types is useful, comparisons between the effectiveness of various programs and methods are scarce. Attempts to synthesize the state of research training are a prerequisite to any efforts to optimize it. Along these lines, because large-scale accounts are usually vague and/or discipline- neutral, it is difficult to know what the perceived advantages and disadvantages are for the bulk of those involved in research training efforts.

This study examines the participation of laboratory researchers in undergraduate/high school student research training efforts. More specifically, it assesses participation among ASPB members and is therefore exclusive to efforts in the plant biology community.

The ASPB (formerly the ASPP, American Society of Plant Physiologists) is a professional organization that promotes the

J.S. Coker, Dep. of Botany and Dep. of Science Education, North Carolina State Univ., Campus Box 7612, Raleigh, NC 27695; and E. Davies, Dep. of Botany and ASPB Education Committee, North Carolina State Univ., Campus Box 7612, Raleigh, NC 27695. Received 10 July 2001. *Corresponding author (jeffreycoker@hotmail.com).

Published in J. Nat. Resour. Life Sci. Educ. 31:44-47 (2002). http://www.JNRLSE.org interests of plant scientists and publishes two well- respected journals, Plant Physiology and The Plant Cell. Its members work in a diverse array of government, industry, and academic environments across six continents and are largely representative of lab-based plant biology researchers, but most are college and university faculty in the USA. This study reflects both the diversity of membership and the desire of the members of ASPB to optimize their efforts in training undergraduate and high school students.

\section{METHODS}

A survey was administered via email through the ASPB's Education Committee. It was sent to everyone on the ASPB mailing list, representing a population of about 5000. Respondents were asked to hit reply to send their responses back to the ASPB main office. Surveys were then forwarded to the authors for analysis. We received 531 full responses, corresponding to a response rate $>10 \%$. Surveys that were not filled out properly or completely were discarded $(<10)$.

Six broad questions were posed, three dealing with undergraduate research and three with high school research. The first question in each group asked if the respondent had supported either undergraduate or high school researchers, the second if they found the experience rewarding, and the third if they would like more information about becoming involved. Respondents were asked to comment on advantages and disadvantages of the respective activity in the second question, and to comment on what types of information they would like in the third. The requests for comments were intentionally left open-ended to avoid biasing or restricting the scope of responses.

Affirmative/negative answers were tallied and summarized. Comments for the second question of each group were categorized according to advantages/disadvantages, then by whether they were student-related or mentor-related, and further arranged into various subcategories. Comments in each subcategory were tallied to assess the prevalence of each advantage/disadvantage. If a respondent mentioned several different advantages or disadvantages in the same comment, they were included in the tally for all relevant categories. Because the survey did not ask about specific advantages or disadvantages, but instead invited open responses, we feel that it would be misleading to perform statistical analyses on the summary frequencies.

\section{MEMBER PARTICIPATION}

The vast majority ( $88 \%$ ) of ASPB members who responded have supported undergraduate researchers, and $97 \%$ of those found the experience(s) rewarding (Table 1). Even though only $12 \%$ of respondents had not supported undergraduates, $34 \%$ wanted to know more about becoming involved. This demonstrates a tremendous interest in undergraduate research.

Somewhat fewer than half have supported high school researchers (Table 1), and $84 \%$ of those found the experience(s) 
rewarding. Thirty-one percent of members had neither participated in nor wanted information about supporting high school researchers. It was not surprising that support for undergraduates was considerably higher than for high school students since most respondents were college faculty.

\section{ADVANTAGES AND DISADVANTAGES OF RESEARCH TRAINING}

Members offered a wide array of potential advantages for both undergraduate and high school researchers (Table 2). Because the survey was open-ended in asking for comments on advantages/disadvantages, responses included advantages for nearly everyone involved in a typical lab. Even so, the vast majority of comments centered around the senior researcher and the undergraduate or high school student. Among the most prevalent advantages mentioned for both activities were the pleasure of mentoring/teaching for mentors (74 total responses), general motivation/learning in plant biology for the student (63 total responses), and creating an enthusiastic and energetic lab environment for everyone 53 total responses).

Several advantages were mostly exclusive to supporting undergraduate researchers. These included an increase in research productivity (46 responses) and recruitment of high quality graduate students (16 responses). The high number of positive responses regarding undergraduate student productivity was a surprise, though only one response reported increasing research output through training high school students.

Many other notable advantages for mentors involved the intellectual benefits of having unbiased people constantly asking questions. Several even stated explicitly that many of their lab's most creative ideas had sprung from the fresh insights of "unknowing" students. Other notable advantages for the students included assistance in career choices, motivation to pursue advanced degrees, coauthorship, and learning lab techniques.

Brandenberger (1990) suggests 16 distinct student benefits from participation in research. These include improving students' work standards, developing practical skills, instilling commitment, providing incentive to excel in course work, providing students with something to talk about with authority, strengthening the bond between the student and institution, improving student-instructor relations, and heightening perseverance, independence, ingenuity, imagination, and intellectual involvement. All of the student benefits (or slight variations from them) that Brandenberger suggested were mentioned by ASPB members.

In general, responses regarding advantages to supporting undergraduate and high school researchers followed the same pattern (Fig. 1 and 2). Advantages for students occupied onethird of the comments in both groups, whereas recruiting/communication and intellectual rewards were mentioned in 9 and $5 \%$ of comments, respectively. The only difference was that a greater percentage of comments involved actual research rewards in the undergraduate setting (31-24\%), whereas more comments involved personal rewards in the high school setting $(28-20 \%)$. In other words, the mentor perception of undergraduates being productive in terms of data production is slightly greater than it is for high school students.

Several professional disadvantages were noted repeatedly for both activities. In contrast to the diverse set of advantages that were mentioned, $58 \%$ of disadvantage comments dealt with one central issue - time (Table 3). "Time consuming" was mentioned explicitly 156 times, often with reference to young researchers producing little publishable data relative to the effort spent training them. On the other hand, 47 people (Table 2) mentioned increases in productivity. A handful of respon-

Table 1. American Society of Plant Biologists member involvement and satisfaction with supporting undergraduate and high school research.

\begin{tabular}{lcc}
\hline Survey question & $\begin{array}{l}\text { No. of } \\
\text { "yes" }\end{array}$ & Percent \\
\hline Undergraduate research & & \\
\hline $\begin{array}{l}\text { 1. Have you supported undergraduate researchers in your lab? } \\
\text { 2. If yes to no. 1, did you find the experience rewarding? }\end{array}$ & 470 & $88 \%$ of 531 \\
$\begin{array}{l}\text { 3. If no to no. 1, would you like to know more about becoming } \\
\text { involved? }\end{array}$ & 21 & $34 \%$ of 61 \\
High school research & & \\
\hline $\begin{array}{l}\text { 4. Have you supported high school researchers in your lab? } \\
\text { 5. If yes to no. 4, did you find the experience rewarding? }\end{array}$ & 261 & $49 \%$ of 531 \\
$\begin{array}{l}\text { 6. If no to no. 4, would you like to know more about becoming } \\
\quad \text { involved? }\end{array}$ & 218 & $84 \%$ of 261 \\
\hline
\end{tabular}

Table 2. Frequencies of American Society of Plant Biologists member comments regarding the potential advantages of supporting undergraduate (UG) and high school (HS) research.

\begin{tabular}{lrrr}
\hline Personal rewards (for mentors) & $\underline{\mathrm{UG}}$ & $\underline{\mathrm{HS}}$ \\
\hline Mentoring and teaching & 56 & 18 \\
Fun-pleasure-general personal reward & 9 & 6 \\
Seeing students present (and win awards for) their research & 5 & 5 \\
Seeing students go on to careers in science & 4 & 2 \\
Satisfying a "moral obligation" (students justify the existence of faculty) & 2 & 0 \\
Intellectual rewards (for mentors) & & \\
Questions of young researchers force the re-evaluation of ideas & 11 & 4 \\
Influx of new/innovative ideas & 8 & 1 \\
Improved recruiting/communications & & \\
Recruitment of high-quality graduate students & 16 & 0 \\
Knowing students personally helps improve teaching/mentoring skills & 5 & 2 \\
Recruitment of high-quality undergraduates & 4 & 5 \\
Recruitment of women and minorities into science & 4 & 2 \\
Networking & 2 & 1 \\
Usefulness of seeing how grad students perform in instructing students & 2 & 0 \\
Source of skilled personnel for future positions in the same faculty lab & 2 & 0
\end{tabular}

Research benefits

Add to lab productivity

Create an energetic and enthusiastic lab environment

Bring an unbiased view of science to the lab

Cheap work force (can be "paid" with course credit, work study, etc.)

Workers for jobs that mentors would consider boring or repetitive

Workers that are more willing to try novel and/or risky projects

Many younger students offer skills in computer technology

Allows research even with a heavy undergraduate teaching load

Undergraduate or high school student benefits

General learning-interest-motivation in plant biology

Assistance in career choices

Motivation/opportunity to do graduate degrees

Become coauthor on a published research paper

Training in laboratory techniques

Reinforced classroom learning (relate theory to practice, etc.)

Build skills in teamwork

Motivation to do honors degree

Job market advantage

Grow as independent critical thinkers

Build self-confidence

Graduate student and post-doc benefits

Improve teaching and mentoring abilities

Assistance on research projects

Motivated to do more, if only to stay ahead of the younger students

Private industry benefits

Prescreen for potential employees 


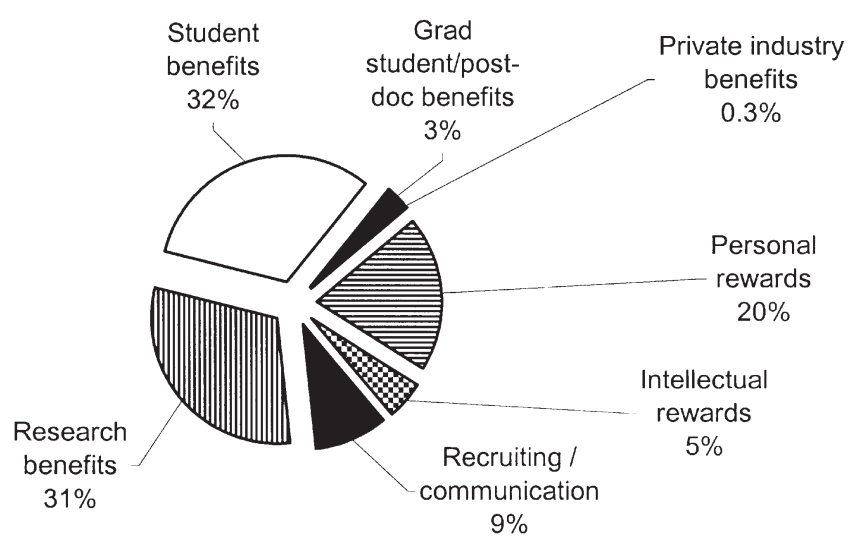

Fig. 1. American Society of Plant Biologists member comments regarding potential advantages of supporting undergraduate researchers.

dents also mentioned that productivity varies widely according to the student and/or project. Concerns about time included the time spent by mentors (129 total responses), the lack of time young researchers have available to work in the lab (62 total comments), and the frustration of watching students graduate soon after the time has been spent teaching them (included in the previous totals). The last two concerns were addressed by a number of respondents who strongly advocated recruiting students, whether in high school or college, to begin as freshman and sophomores. Students then have the opportunity to stay several years in a lab and contribute significantly.

Several student-based disadvantages were mentioned that could be a factor in any teaching situation such as insufficient background (30 total responses), lack of motivation/interest (14 total responses), and immaturity (10 total responses). On the whole, these comments were not overly abundant and normally referred to high school students. Usually when mentioned, the respondents were speaking of particular situations and not all undergraduates or all high school students.

A few people also mentioned potential monetary disadvantages such as increased costs, waste of materials, or damage of equipment (18 total responses).

As stated previously, an overwhelming number of ASPB members who have supported undergraduate and high school

Table 3. Frequencies of American Society of Plant Biologists member comments regarding the potential disadvantages of supporting undergraduate (UG) and high school (HS) research.

\begin{tabular}{lrr}
\hline Student-based disadvantages & UG & HS \\
\cline { 2 - 3 } Short time commitment of students & 41 & 21 \\
Insufficient background in science & 8 & 22 \\
Lack of motivation/interest & 7 & 7 \\
Difficulties working independently/reliably & 7 & 5 \\
Scheduling problems & 6 & 3 \\
Waste of materials/damage of equipment & 6 & 2 \\
Immaturity & 1 & 9 \\
Transportation problems & 1 & 2 \\
Safety concerns & 1 & 2 \\
Overbearing parents & 0 & 4 \\
Mentor-based disadvantages & & \\
Time consuming for mentor & 84 & 45 \\
Can be less productive in terms of publishable data & 13 & 7 \\
Requires a great deal of work (to train students, etc.) & 9 & 15 \\
Costly financially/insufficient funding for students & 8 & 2 \\
Instructing students is not rewarded professionally & 5 & 1 \\
Project is peripheral to lab's main interests & 1 & 2 \\
Difficulties relating to younger students & 1 & 1 \\
Legal hassles with accident insurance coverage & 1 & 0 \\
Looked down upon by academic peers & 1 & 0 \\
\hline
\end{tabular}

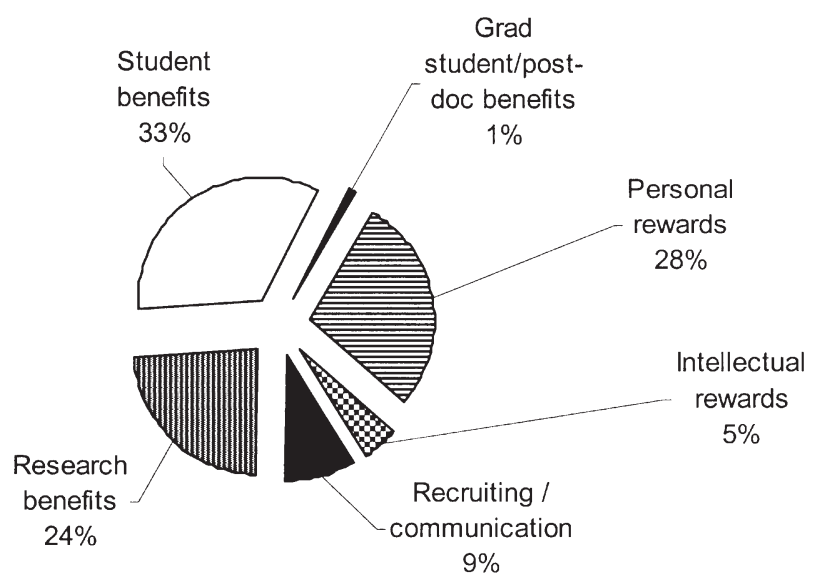

Fig. 2. American Society of Plant Biologists member comments regarding potential advantages of supporting high school researchers.

researchers found it rewarding overall (Table 1). Participant comments proved more discriminating, however. The advantage to disadvantage ratios tabulated from all comments were 1.9:1 for undergraduate research and 0.7:1 for high school research (Fig. 3), again showing support for both groups but considerably more for undergraduate research.

Overall, the survey indicates that the ASPB membership is both supportive of and active in research training, especially for undergraduate students. These conclusions furnish optimism, yet must be taken with reservation until more is known about the quality and extent of these research experiences. We hope that this study will serve as a benchmark for future surveys and a foundation for more process-product oriented studies that will associate particular practices with particular outcomes. In particular, future studies should include the following: determination of the specific type of support given by the mentor; approximate numbers of students supported by individual mentors; more precise classification of the extent of mentor satisfaction; and specific examples of lab projects and training techniques that have been especially effective/ineffective. We expect that future studies seeking to further assess and optimize research training and other educational efforts in plant biology will be of great value.

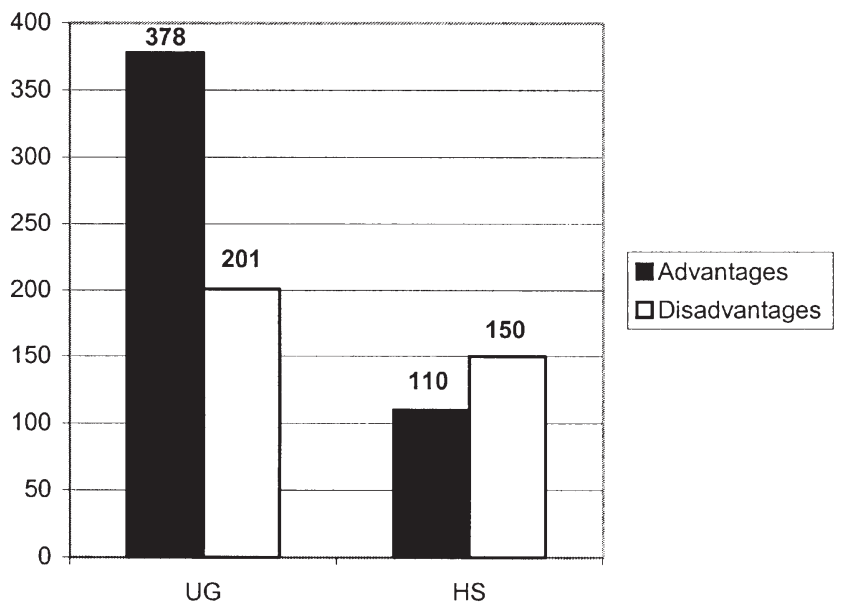

Fig. 3. Number of American Society of Plant Biologists member comments regarding undergraduate and high school research. 


\section{REFERENCES}

Austin, C.A. 1997. A survey of final-year undergraduate laboratory projects in biochemistry and related degrees in Great Britain. Biochem. Educ. 25:12-14.

Beer, R.H. 1995. Guidelines for the supervision of undergraduate research. J. Chem. Educ. 72:721-722.

Boersma, S., M. Hluchy, G. Godshalk, J. Crane, D. DeGraff, and J. Blauth. 2001. Student- designed interdisciplinary science projects. J. College Sci. Teach. 30:397-402.

Brandenberger, J.R. 1990. The multifaceted case for undergraduate research. CUR Newsl. XI:23-29.

Chaplin S.B., J.M. Manske, and J.L. Cruise. 1998. Introducing freshmen to investigative research: A course for biology majors at Minnesota's University of St. Thomas. J. College Sci. Teach. 27:347-350.

Craig, N.C. 1999. The joys and trials of doing research with undergraduates. J. Chem. Educ. 76:595-597.

Druger, M. 1998. Teaching versus research: An ongoing issue at the college level. J. Nat. Resour. Life Sci. Educ. 27:134-135.

Durso, F.T. 1997. Corporate-sponsored undergraduate research as a capstone experience. Teaching of Psychology 24:54-56.
Henderson, L., and C. Buising. 2000. A research-based molecular biology laboratory. J. College Sci. Teach. 30:322-327.

Heppner, F. 1996. Learning science by doing science. Am. Biol. Teach. 58:372-374.

Krasny, M.E. 1999. Reflections on nine years of conducting high school research programs. J. Nat. Resour. Life Sci. Educ. 28:17-23.

Levesque, M.J., and M. Wise. 2001. The Elon experience: Supporting undergraduate research across all disciplines. CUR Quarterly, March: 113-116.

McLean, R.J.C. 1999. Original research projects: A major component of an undergraduate microbiology course. J. College Sci. Teach. 29:38-40.

Nikolova Eddins, S.G., D.F. Williams, D. Bushek, D. Porter, and G. Kineke. 1997. Searching for a prominent role of research in undergraduate education: Project Interface. Journal on Excellence in College Teaching 8:69-81.

Ortez, R.A. 1994. Investigative research in nonmajor freshman biology classes. J. College Sci. Teach. 23:296-300.

Schowen, K.B. 1998. Research as a critical component of the undergraduate educational experience. p. 73-81. In K.B. Schowen (ed.) National Academy Press, Washington, DC

Seago, J.L., Jr. 1992. The role of research in undergraduate instruction. Am. Biol. Teach. 54:401-405. 